\title{
Laryngeal Stenosis from Trapped Overflowed Head Scarf in the Wheel of a Moving Motor Cycle: A Case Report
}

\author{
Stanley Baba Amutta*, Mohammed Abdullahi, Daniel Aliyu, Caleb Manya \\ Department of Otorhinolaryngology, Usmanu Danfodiyo University Teaching Hospital, Sokoto, Nigeria \\ Email: *samutta14@gmail.com
}

How to cite this paper: Amutta, S.B., Abdullahi, M., Aliyu, D. and Manya, C. (2016) Laryngeal Stenosis from Trapped Overflowed Head Scarf in the Wheel of a Moving Motor Cycle: A Case Report. Case Reports in Clinical Medicine, 5, 347-352. http://dx.doi.org/10.4236/crcm.2016.510053

Received: August 22, 2016

Accepted: September 27, 2016

Published: September 30, 2016

Copyright $\odot 2016$ by authors and Scientific Research Publishing Inc. This work is licensed under the Creative Commons Attribution International License (CC BY 4.0).

http://creativecommons.org/licenses/by/4.0/

\section{(c) (i) Open Access}

\begin{abstract}
Introduction: Laryngeal stenosis is partial or circumferential narrowing of the endolaryngeal airway from congenital or acquired causes. It can present with life threatening upper airway obstruction, and the goal of treatment is restoration of good quality voice, respiration and laryngeal competence. We report a case of laryngeal stenosis following strangulation by a trapped overflowed head scarf, whilst being transported on a motor cycle and highlighted the treatment challenges. Methodology: A case of laryngeal stenosis studied, clinical findings, investigation results and treatment analysed. Results: A 70-year-old Nigerian elderly woman presented with three weeks' history of hoarseness and progressive difficulty in breathing, following pulling of her long head scarf into the back wheel of the motor cycle taking her home. She had immediate loss of consciousness, which lasted for about 60 minutes. There was associated bout of cough while eating. Examination revealed life threatening upper airway obstruction. X-ray soft tissue neck showed soft tissue mass obliterating larygotracheal air column. Flexible nasopharyngolaryngoscopy showed grossly distorted laryngeal inlet with invisible vocal cords. CT scan of the larynx showed multiple and displaced fractures of the laryngeal cartilages. Microlaryngoscopy findings were pin-hole laryngeal lumen with firm collapsed mucosa. Emergency tracheostomy was done to relieve the upper airway obstruction. Attempts were made to excise the collapse mucosa and insert a stent proved difficult. Referral for endoscopic laser excision was caution because of the potential risk of aspiration. She was counselled and coping well with the tracheostomy.
\end{abstract}

\section{Keywords}

Laryngeal Stenosis, Strangulation, Treatment, Sokoto 


\section{Introduction}

Laryngeal stenosis is a congenital or acquired narrowing of the airway that may affect the supraglottis, glottis and subglottis [1]. The subglottis is the most common site of involvement [1]. Adult laryngeal stenosis can arise from the following causes: external laryngotracheal trauma from penetrating tissue injury, high or low velocity impact blunt force neck trauma, endolaryngeal trauma from endotracheal intubation, posttracheostomy, post-microlaryngeal resection and post radiotherapy [2] [3]. The other less common causes include granulomatous infection from tuberculosis, scleroderma and fungal histoplasmosis. Chronic inflammatory diseases like sarcoidosis seldomly lead to laryngeal stenosis. Moreover, collagen vascular diseases such as wegener's granulomatosis and relapsing polychondritis often result in laryngeal stenosis [4]. Benign and malignant laryngeal neoplasia can also lead to laryngeal stenosis and extrinsic compression from giant multinodular goitre and thyroid malignancy [2].

An essential part of the management is endoscopic evaluation of the airways in the operating room [2]. Treatment options are endoscopic or open surgical approaches. However, the choice of treatment option depends greatly on patient's symptoms, site of involvement and degree of stenosis [5].

We present this case because of the treatment challenges encountered in her management.

\section{Case Report}

A 70-year-old Nigerian woman presented with three weeks' history of hoarseness and progressive difficulty in breathing, following pulling of her long and overflowed head scarf into the back wheel of the motor cycle on which she was being conveyed home. She had immediate loss of consciousness, which lasted for about 60 minutes. There was associated bout of cough while eating suggesting aspiration. Examination revealed features of life threatening upper airway obstruction and barely audible speech. X-Ray soft tissue neck showed soft tissue mass obliterating larygotracheal air column Figure 1, flexible nasopharyngolaryngoscopy showed grossly distorted laryngeal inlet with invisible vocal cords and its movement as shown in Figure 2. Serial axial slices of the CT scan of the larynx showed multiple and displaced fractures of the laryngeal cartilages, isodense translaryngeal mass and pin-hole laryngeal lumen as shown in Figures 3-5. Microlaryngoscopy findings were pin-hole laryngeal lumen with firm collapsed endolaryngeal mucosa.

She had an emergency tracheostomy and was hospitalized in our Centre for five weeks because of the problem of aspiration during meal. Aspiration stop after three weeks on admission in the hospital. Additionally, the tracheostomy was complicated by excessive crusts formation below the tip of the tracheostomy tube in the trachea. The crusts usually formed a plug, which cause upper airway obstruction. She experienced this problem one to two times every week for the first three weeks on admission. The plug of crusts was successfully managed by instilling about one millimeter of $0.9 \%$ normal saline into the trachea via the tracheostomy tube to soften, and then sucked it 


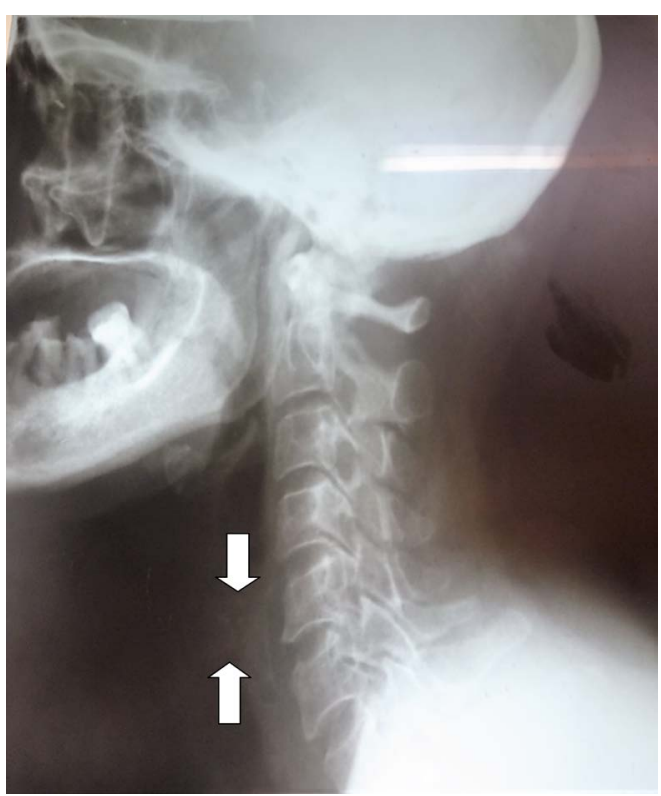

Figure 1. Lateral view of X-ray soft tissue neck showing soft tissue mass obliterating laryngotrachael air column (between the white arrows).

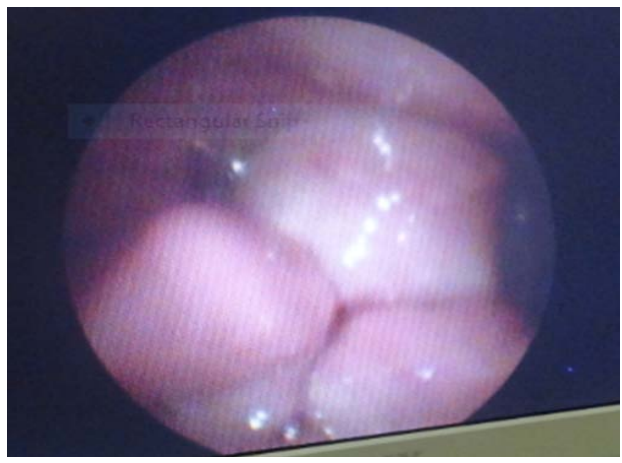

Figure 2. Distorted view of laryngeal inlet on flexible laryngoscopy.

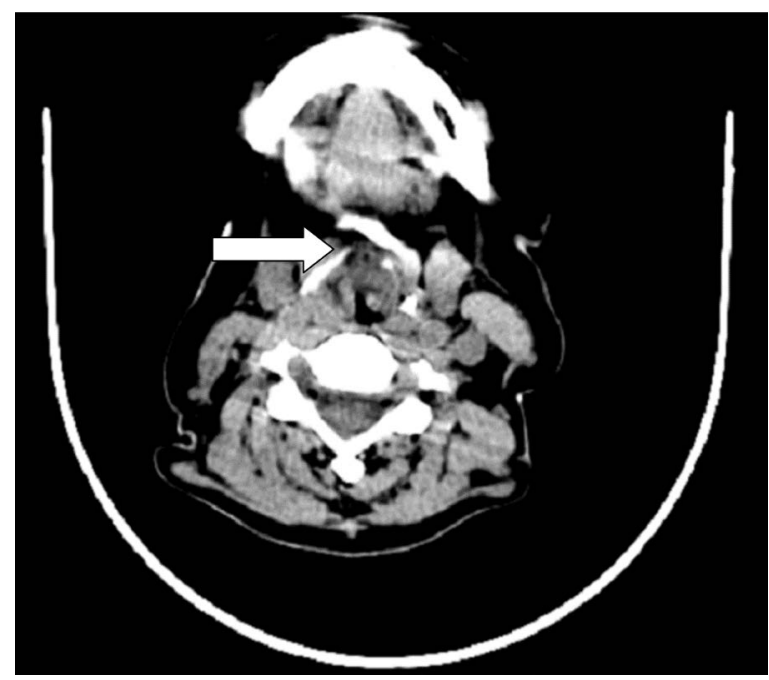

Figure 3. Displaced fracture of the thyroid cartilage (white arrow). 


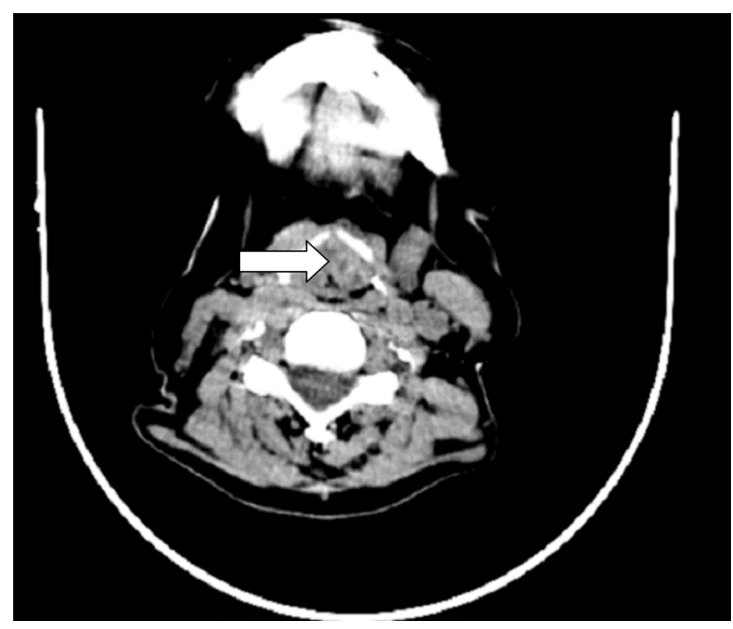

Figure 4. White arrow shows isodense translaryngeal mass.

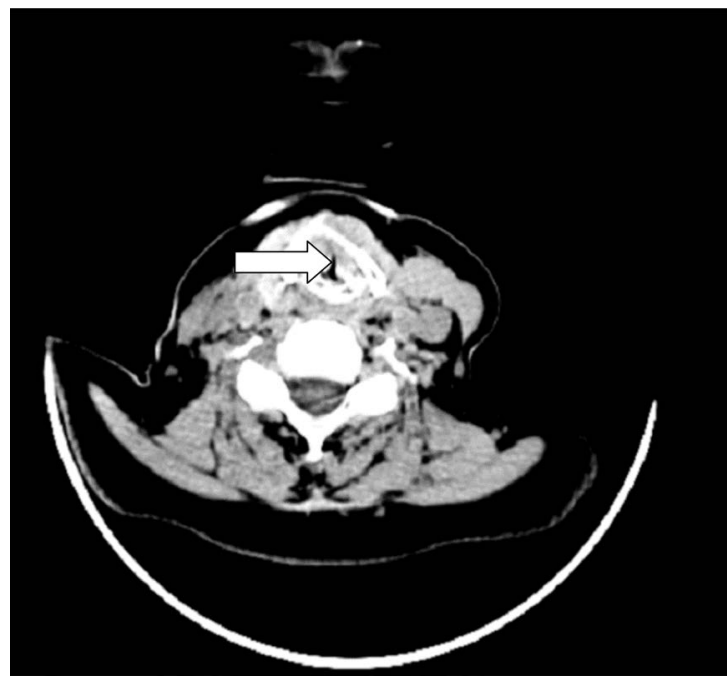

Figure 5. Pin-hole laryngeal lumen showed by white arrow.

out with suction machine. Sometime, the tracheostomy tube had to be completely removed and tracheostoma kept open with a trachea dilator, whilst patient was encouraged to cough to expel the mucoid crusts via the tracheostomy stoma. Tracheostomal swab and swab from suction tubings, to rule out peristomal bacteria colonization after the tracheostomy, yielded no growth. However, she was placed on empirical oral antibiotic (Tablet Augmentin $1 \mathrm{~g} 12$ hourly and Metronidazole $400 \mathrm{mg} 8$ hourly for fourteen days).

Attempts to excise the collapse mucosa endoscopically and insert a stent proved difficult. Referral for endoscopic laser excision was caution because of the potential risk of aspiration. Therefore, she was counselled to make do with the tracheostomy and she is coping well.

\subsection{Discussion}

Soft tissue damage of the laryngeal lumen can result in: 1) mucosal loss, 2) Adhesions, 
3) Organization of haematoma within paraglottic, pre-epiglottic and interarytenoid space [2].

Glottic insufficiency can result from web formation, arthrodesis of arytenoid and damage recurrent laryngeal nerve [2]. Displaced fractured cartilaginous framework usually heal with fibrosis with its's fibrocyte possessing directional memory, therefore, incising and separating fibrous tissue often result to a dense fibrous tissue. Possible solution is excision and grafting (rib, hyoid, thyroid cartilage, auricular and nasal septal cartilage) to re-establish structural support [6]-[9]. It is worthy of note that none of these graft is ideal. Enough mucosa should be preserved when the structural support is re-established. This can be augmented by skin or buccal mucosa graft. Endoscopic approach in the surgical management decreased morbidity, shorter hospital stays and tolerance of repeated procedure [10]. In 1972 Strong and Jacko first reported endoscopic treatment of laryngotracheal stenosis with $\mathrm{CO}_{2}$ laser [2].

The patient in this case report had both mucosal and displaced cartilaginous damage with resultant dense fibrosis, therefore, the choice of laser resection and dilatation were considered inappropriate and discarded. Furthermore, laser excision will worsen her mild aspiration because of the immobility of the vocal cords. Open surgical approach was another challenge. She was in advance age and the degree of the stenosis (transglottic) means that she would require multiple stage procedure, and there is no guarantee that resection and grafting will be successful.

Overall, the goal of surgery is to establish satisfactory airway and allow decanulation, good voice and laryngeal competence. The patient may never be decanulated or regain good voice if the stenosis involves the glottis or supraglottic larynx [2]. The patient in this case report was advised to make do with the tracheostomy because her laryngeal stenosis involved the supraglottic, glottic and subglottic regions of the larynx. Reconstruction may be complicated by glottic incompetence and re-stenosis. Generally, the most frequent cause of failure of treatment is scar formation and re-stenosis.

The cessation of the aspiration prior to her discharge home could be attributed to the collapsed, distorted laryngeal inlet, acceptance of the damage to her larynx couple with swallowing exercises. Excessive mucoid secretion, crusting and cough are common immediate complications of tracheotomised and laryngectomized patient [11]. Presumably, she was given empirical antibiotic treatment because peristomal infection and tracheitis could be responsible for her troublesome tenacious crusting.

She was discharged home in good mood after learning how to safely change and clean her tracheostomy tubes and had been on a 2 year, 3-month follow-up in our ENT out-patient clinic. She is coping well with the tracheostomy, and free from the aspiration and excessive crust formation.

\subsection{Conclusion}

Permanent tracheostomy may be the treatment of choice for severe translaryngeal stenosis in an elderly patient with mild glottis incompetence, and extensive endolaryngeal and cartilaginous skeletal framework damage. 


\section{References}

[1] Mark, E.G. and Arlen, D. (2016) Laryngeal Stenosis. http://emedicine.medscape.com/article/86/867177

[2] Lisa, P. (2008) Laryngeal Trauma and Stenosis, In: Michael, G., Ed., Scott's Browns Otorhinolaryngology, Head and Neck Surgery, 7th Edition, Vol. 2, Hodder Arnolds, London, 2271-2286.

[3] Kavardian, K., Jafarzadeh, A., Hajipour, A. and Zolfarghari, N. (2011) Subglottic Stenosis Following Percutaneous Tracheostomy: A Single Centre Report as a Descriptive Study. Acta Otorhinolaryngologica Italica, 31, 239-242.

[4] Stevens, M., Chang, A. and Simpson, C. (2013) Supraglottic Stenosis: Aetiology and Treatment of a Rare Condition. Annals of Otology, Rhinology \& Laryngology, 122, 205-209. http://dx.doi.org/10.1177/000348941312200310

[5] Xu, W., Han, D., Hu, H., Chen, X., Li, H., et al. (2009) Endoscopic Mucosal Suturing of Vocal Fold with Placement of Stent for the Treatment of Glottis Stenosis. Head \& Neck, 31, 732-737. http://dx.doi.org/10.1002/hed.21024

[6] Wolf, M., Shapira, Y., Talmi, Y., Novikov, I., Kronenberg, J., et al. (2011) Laryngotrachael Anastomosis: Primary and Revised Procedures. Laryngoscope, 111, 622-627. http://dx.doi.org/10.1097/00005537-200104000-00012

[7] Max, M. and Bernard, R. (1993) Laryngotrachael Reconstruction for Subglottic Stenosis. Annals of Otology, Rhinology \& Laryngology, 102, 176-181. http://dx.doi.org/10.1177/000348949310200303

[8] Prescott, C. (1998) Protocol for Management of the Interposition Cartilage Graft Laryngotracheoplasty. Annals of Otology, Rhinology \& Laryngology, 97, 239-242. http://dx.doi.org/10.1177/000348948809700305

[9] Eliachar, I., Roberts, J., Levin, H. and Tucker, H. (1987) Laryngotachael Reconstruction: Sternohyoid Myocutaneous Rotatory Door Flap. Archives of Otolaryngology Head and Neck Surgery, 113, 1094-1097. http://dx.doi.org/10.1001/archotol.1987.01860100072025

[10] Parker, N., Bandyopadhyay, D., Misino, S. and Goding, G. (2013) Endoscopic Cold Incision, Ballon Dilation, Mitomycin C Application, and Steroid Injection for Adult Laryngotrachael Stenosis. Laryngoscope, 123, 220-225. http://dx.doi.org/10.1002/lary.23638

[11] Kramp, B., Donat, M., Dommerich, S., Pau, H.W. and Podbielski, A. (2009) Prospective Controlled Study of Microbial Colonization of the Trachea in Tracheotomised and Laryngectomized Patients with HME (Heat and Moisture Exchanger). Acta Oto-Laryngologica, 129, 1136-1144. http://dx.doi.org/10.1080/00016480802572517 
Submit or recommend next manuscript to SCIRP and we will provide best service for you:

Accepting pre-submission inquiries through Email, Facebook, LinkedIn, Twitter, etc. A wide selection of journals (inclusive of 9 subjects, more than 200 journals)

Providing 24-hour high-quality service

User-friendly online submission system

Fair and swift peer-review system

Efficient typesetting and proofreading procedure

Display of the result of downloads and visits, as well as the number of cited articles

Maximum dissemination of your research work

Submit your manuscript at: http://papersubmission.scirp.org/

Or contact crcm@scirp.org 